\title{
O ENSINO JURÍDICO SOB A ÓTICA DA GAMEFICAÇÃO
}

\author{
Paulo Vitor Valeriano dos Santos ${ }^{1}$ \\ Luiza Machado Farhat Benedito ${ }^{2}$
}

\begin{abstract}
Resumo
O modelo atual de ensino nas faculdades de Direito repete uma realidade antiga, transmissiva e cartesiana de conhecimento. É de suma importância que metodologias inovadoras de ensino sejam promovidas com o escopo de atualizar os mecanismos do sistema de ensino. A evolução deste sistema exige que os docentes superem a necessidade de engajar os estudantes e competir com os recursos tecnológicos. Tecer reflexões acerca da disseminação de novas possibilidades de ensino nas faculdades de Direito e das formas de implementá-las é tarefa urgente. O presente estudo apresenta a Gameficação como uma metodologia inovadora e capaz de promover um aprendizado eficaz.
\end{abstract}

Palavras-Chaves: Direito; gameficação; inovação; metodologias; ensino jurídico.

\section{LEGAL EDUCATION UNDER THE VIEW OF GAMING}

\begin{abstract}
The current model of teaching in law schools repeats an old, transmissive and Cartesian reality of knowledge. It is of the utmost importance that innovative teaching methodologies be promoted with the scope of updating the mechanisms of the education system. The evolution of this system requires that teachers overcome the need to engage students and compete with technological resources. It is an urgent task to think about the dissemination of new teaching possibilities in law schools and how to implement them. The present study presents Gamefication as an innovative methodology capable of promoting effective learning.
\end{abstract}

Keywords: Gamification; Innovation; Right; Methodologies; Legal Education.

\footnotetext{
${ }^{1}$ Advogado. Mestrando em Direito Público pela Universidade FUMEC. Pós-Graduado em Direito Público pela Universidade Anhanguera-UNIDERP. Bacharel em Direito pela Universidade Federal de Juiz de Fora - UFJF. Lattes: <http://lattes.cnpq.br/4237134008080174>

${ }^{2}$ Mestra em Direito pela Universidade FUMEC. Pesquisadora no projeto de pesquisa Design Instrucional e Inovação das Metodologias de Ensino Jurídico (FAPEMIG). Lattes: <http://lattes.cnpq.br/9301354857281204>. Assistente Judiciária do TJMG. Professora.
} 


\section{INTRODUÇÃO ${ }^{3}$}

O presente estudo propõe-se a pesquisar a aplicação da Gamificação na construção do conhecimento, com foco em sua eficácia no que tange o ensino jurídico.

Será abordada de forma sucinta a deficiência da forma tradicional de ensino nas academias jurídicas e a necessidade de resgatar o engajamento dos alunos de Direito. A discussão irá se aprofundar e tratar de forma crítico-reflexiva a metodologia inovadora da Gameficação e a sua potencialidade para auxiliar na mudança do paradigma atual de ensino: cartesiano e transmissivo. Para tanto, será feito um recorte dessa metodologia para o campo da educação jurídica, contudo, sem deixar de apontar sua origem na seara empresarial.

É nítida a defasagem do ensino contemporâneo nas faculdades de Direito, o que tem produzido resultados cada vez mais questionáveis e contribuído, significativamente, para o desinteresse e apatia dos docentes dos cursos jurídicos em geral, não somente da graduação na Ciência do Direito. Neste sentido, a Gameficação surge como uma alternativa para se inovar a forma de ensinar e de aprender, da mesma forma que já modificou paradigmas na esfera empresarial, onde se inaugurou a implementação da técnica em ambientes profissionais e para o aprendizado.

A utilização de metodologias inovadoras no Ensino Jurídico é tema controvertido e objeto de polêmica entre discentes, docentes e colegiados. Muito dessa resistência se deve ao fato de que há um modelo sedimentado há muito anos, focado apenas na transmissão direta de conteúdo, geralmente dimensionado pela aprovação na prova de suficiência da Ordem dos Advogados do Brasil e demais exames para carreiras jurídicas e/ou serviços públicos em geral.

A Gameficação se vale de técnicas e mecânicas de jogos para aprimorar questões educacionais através do resgate no interesse do jovem de hoje - inserido em um mundo dominado pela internet, redes sociais e congêneres - tornando smartphones, tablet's e outros equipamentos em aliados e não mais rivais da atenção dos estudantes.

No presente estudo será analisado, sugerido e relatado formas de aplicação da Gameficação, demonstrando-se que o trabalho interativo e dinâmico é capaz de construir um conhecimento mais sólido do que a mera transmissão literal de conteúdo.

Com os resultados e apontamentos que serão evidenciados, será possível concluir, a

\footnotetext{
${ }^{3}$ Os autores agradecem o apoio recebido da Fundação de Amparo à Pesquisa do Estado de Minas Gerais FAPEMIG e da Universidade Fumec, para realização da pesquisa e divulgação dos seus resultados.
} 
partir de uma concepção reflexiva, a viabilidade e a necessidade da aplicação da Gamificação no ensino nas faculdades de Direito brasileiras, bem como se essa tem ou não o condão de superar o desgaste do sistema educacional jurídico pátrio, atual.

Este é o problema que esta pesquisa procura enfrentar, por meio do método dedutivo e com fundamento nos referenciais teóricos estabelecidos por Ysmar Viana, na obra: Gamification, Inc: como reinventar empresas a partir de jogos; por FARDO, na obra: A gamificação aplicada em ambientes de aprendizagem; e por Márcio Caldas, na obra: Gamification e o Direito.

\section{BREVE REFLEXÃO SOBRE A FALÊNCIA DO MODELO ATUAL DE ENSINO}

Parte significativa das pesquisas sobre o ensino no Brasil evidencia, a cada dado divulgado, uma nova decepção. O ensino jurídico no Brasil, de uma forma geral, reflete uma situação mais generalizada, com vasto desinteresse e até pessimista do que é a conjuntura do ensino nas escolas de ensino médio nacional. Há anos as péssimas condições estruturais, sejam físicas, financeiras, organizacionais, desorganização funcional, evasões e a comprometida qualificação profissional dos discentes apontam para um fracasso sintomático. A insistência em se repetir um modelo centenário de ensino, que não acompanhou a evolução da sociedade, tem prejudicado toda a cadeia de ensino.

Os resultados em exames jurídicos são pífios e o mercado cada vez mais abastecido com profissionais menos qualificados. Estas são apenas algumas das questões que versam sobre a urgente necessidade de se repensar o ensino jurídico nas academias de Direito, objeto do presente estudo.

No paradigma vigente milita o instrucionismo, entendido como armazenamento e entrega de informações, ele fundamenta-se no princípio de que a ação de ensinar é fortemente relacionada com a transmissão de informação ao aluno. Sob esse ponto de vista, a melhora do ensino consiste em aperfeiçoar as técnicas de transmissão de informação do professor e a aquisição da mesma pelo aluno (VALENTE, 1993).

Nesse sentido ensina Luiza Benedito e Frederico Gabrich (2017):

$\mathrm{Na}$ realidade, os cursos jurídicos do Brasil continuam sendo desenvolvidos a partir da lógica do conflito e do processo judicial (GABRICH, 2010). E isso é evidente nas diretrizes curriculares da maioria das disciplinas dos cursos de Direito, o que também corre no direito de família e no direito empresarial. 
Tal característica está intrinsecamente ligada ao caráter fundamentalmente instrucionista da docência jurídica, que pauta-se, quase exclusivamente, na leitura do texto da lei, na explanação de conceitos (e quase nunca da finalidade dos institutos jurídicos), no pressuposto de um conflito (que precisa ser solucionado ou prevenido), no saber quase que exclusivo dos professores, desenvolvido por meio de um discurso dogmático e unidirecional.

De fato, o instrucionismo é uma metodologia de ensino que consiste na transmissão de conteúdos fundamentalmente por meio de aulas expositivas e unidirecionais (monólogos), numa abordagem linear e dogmática, na qual exigese do aluno a memorização e reprodução do conteúdo repassado pelo professor. Portanto, no instrucionismo o discente tem um papel passivo (escutar, assimilar e decorar as informações), ao passo que o docente é o polo ativo e o centro da sala de aula (BENEDITO; GABRICH, 2017).

Contudo, esse modelo é rígido, polarizando educandos e educadores. Uma sociedade dinâmica que cada vez mais aproxima os papéis contributivos de ambos em sala de aula não suporta mais este modelo cartesiano e antiquado. A formalidade priorizada pelo modelo instrucionista gera uma desmotivação nos alunos e a fuga de seu interesse para as outras formas interativas de acesso à informação, como os objetos e meios eletrônicos, por exemplo.

Já para o paradigma construtivista, a construção do conhecimento não depende apenas do professor, mas também da interação do mesmo com seus alunos, e da interação destes entre si e com o meio ambiente no qual estão inseridos, pois é fundamental que a aprendizagem ocorra de forma colaborativa (ZEVE at al.,2000).

Ainda sobre o assunto, Patrícia Scherer Bassani:

A aprendizagem construtivista considera o ambiente como sendo o cenário onde acontece o processo de integração, que promove e desencadeia um processo de construção interna de significados. Assim, o cenário se torna um ambiente no qual professores e alunos desenvolvem ações que podem levar a processos de aprendizagem (BASSANI et al, 2006. p.2).

Igualmente são os ensinamentos de Luiza Benedito e Frederico Gabrich (2017):

“(...) é evidente que o instrucionismo é importante para a educação, tanto que ainda é o modelo mais aplicado na maioria das escolas e universidades, e a principal metodologia que permitiu o desenvolvimento do conhecimento alcançado pela humanidade até o momento.

Porém, o uso excessivo e quase exclusivo desse modelo está desconectado com as inovações, com o fluxo contínuo e livre de informações, bem como com o pluralismo de ideias e de concepções de ensino e de aprendizagem determinados pela era do conhecimento que marca este século. 
Não obstante, para instigar o interesse do discente, bem como para deslocar o aluno do polo passivo (de mero receptor de informações e conteúdos) e despertá-lo para o aprendizado, é imprescindível repensar o ensino jurídico, bem como a pesquisa e a implementação de variadas e inovadoras metodologias e métodos de ensino. Nesse sentido, o construtivismo e o construcionismo são metodologias importantes para essa necessária evolução (BENEDITO; GABRICH, 2017).

A substituição da transmissão pela construção do conhecimento é tarefa que urge a ser implantada nas faculdades de Direito. O resgate do interesse dos acadêmicos através de metodologias inovadoras de ensino é possível e viável, além de apontar para uma possibilidade de reversão desse quadro caótico do ensino que se vive nos dias de hoje.

\section{METODOLOGIAS INOVADORAS DE ENSINO}

Hodiernamente, vive-se em uma sociedade dinâmica e multifacetada. A evolução dita ritmos acelerados de mudanças e coloca toda e qualquer estagnação em cheque. Infelizmente, as novas gerações de estudantes de Direito enfrentam essa realidade ativa, contudo mantêm-se inseridos em um sistema educacional obsoleto.

Os novos interesses das gerações $\mathrm{Y}^{4}$ e $\mathrm{Z}$ são completamente diferentes daqueles que as gerações $\mathrm{X}$ buscavam em meados do século passado. As mudanças culturais, de mercado e de comportamento modificam os padrões estabelecidos na sociedade, e com o ensino não é diferente.

Há tempos o mercado exige advogados, juízes, promotores e todos os profissionais dos demais cargos jurídicos elevado padrão e desenvolvimento no conhecimento técnico, mas também demanda que estes conhecimentos possam ser aplicados de forma transdisciplinar e humana. Sobre o assunto leciona Frederico de Andrade Gabrich:

O ensino jurídico precisa evoluir para reconhecer a importância atual da transdisciplinaridade e a sua capacidade de restabelecer a força, a significação e o interesse do ensino do Direito, especialmente diante dos novos paradigmas da contemporaneidade e dos interesses das novas gerações de estudantes e de profissionais do Direito (GABRICH, 2013, p.16).

\footnotetext{
${ }^{4}$ Geração X: Nascidos até 1970. Geração Y: Nascidos entre 1970 e 1990. Geração Z: Nascidos entre 1992 e 2010. Deve-se ficar claro que as datas são relativas e servem para traçar parâmetros não devendo serem entendidas numa compreensão hermética, mas sim como um direcionamento abrangente.
} 
Contudo as técnicas tradicionais não são adeptas às inovações e os alunos acabam imersos em um ambiente de desinteresse, com excesso de conteúdo transmitido de maneira mecânica, o que leva, geralmente, à baixa absorção do mesmo e, consequentemente, limita a compreensão, o desenvolvimento do aprendizado e a construção do conhecimento pelos discentes.

A desqualificação profissional deu início a um círculo vicioso de pouca demanda, prática de baixos preços, clientela insatisfeita e desvalorização do jurista.

É preciso renovar o ensino jurídico, e para isso podemos tangenciá-lo com algumas metodologias inovadoras. A visão do Direito como ciência do conflito e do processo judicial, bem como do litígio, são entraves à mudança do modelo mental com que professores, alunos e sociedades enxergam a Ciência do Direito. A desconstrução na forma de ensinar e aprender o Direito tende a ser o passo inicial capaz de desencadear uma alteração nesse paradigma.

São vários os arranjos inovadores do ensino que podem ser aplicados ao ensino jurídico. Entre eles podemos citar: storytelling, sala de aula invertida, mapas mentais, brainstorming, design instrucional, Lego Serious Play, dentre vários outros, cada um com sua potencialidade e sua capacidade de contribuir para modificar o modelo vigente.

Para o presente estudo foi escolhida uma dessas metodologias: a Gameficação.

\section{GAMEFICAÇÃO}

O termo gameficação é denso e amplo, sendo vastas as possibilidades de sua utilização. Portanto, não é intenção do presente artigo exaurir todas suas potencialidades nos inúmeros campos possíveis.

Quando se fala em Gamification é comum que a primeira ideia seja o seu entendimento exclusivamente como o uso de jogos eletrônicos no ensino. No entanto, a Gameficação vai muito além disso.

Para Karl M. Kapp esta técnica envolve o uso das mecânicas, ideias e estética de jogos para engajar pessoas, motivar ações, promover o aprendizado e solucionar problemas (KAPP, 2012). Conceito semelhante encontra-se na plataforma de pesquisa Wikipedia ${ }^{5}$, bem como na definição de Ysmar Viana:

\footnotetext{
${ }^{5}$ Fonte disponível em:< https://pt.wikipedia.org/wiki/Ludifica\%C3\%A7\%C3\%A3o >. Gamificação: uso de mecânicas dos jogos em contextos diversos, com o objetivo de incrementar a participação e gerar engajamento e comprometimento por parte de potenciais usuários. Acesso em: 7 abr. 2018.
} 
O desenvolvimento da gamificação - também referida como ludificação -, portanto, provém de uma constatação um tanto óbvia: seres humanos sentem-se fortemente atraído por jogos. Ao longo dos séculos, praticamente todas as civilizações conhecidas estiveram associadas a algum tipo de competição importante para a estruturação social da comunidade a qual pertenciam (VIANNA, 2013, pg. 16).

Contudo, faz-se mister ressaltar o alerta do autor para um grande erro interpretativo que vem sendo comum quando se trata da Gamificação:

\begin{abstract}
Ainda que seja um dos temas mais festejados do momento, a gamificação, como conceito, tem sido sistematicamente mal interpretada; é errado pensar que se trata de uma ciência que se debruça sobre o ato de criar jogos, mas sim uma metodologia por meio da qual se aplicam mecanismos de jogos à resolução de problemas ou impasses em outros contextos (VIANNA, 2013. pg. 1).
\end{abstract}

Portanto, frise-se: a Gamificação não significa necessariamente criar um jogo em si, tampouco está necessariamente vinculada a games eletrônicos. Estas possibilidades estão sim inseridas em seu amplo rol de possibilidades, mas a metodologia ultrapassa essa ideia. A gamification pode ser aplicada nos mais diversos campos do conhecimento e objetiva engajar pessoas, resolver problemas e melhorar o aprendizado, motivando ações e comportamentos em ambientes fora do contexto de jogos.

Essa metodologia engajadora surgiu e foi difundida no ramo empresarial, dos negócios, como uma maneira de incentivar o consumo e a fidelização de clientes pelas empresas e engajar colaboradores. O termo foi criado por um programador de computadores e pesquisador britânico chamado Nick Pelling em 2003 e ganhou notoriedade através da designer de games norte americana Jane MCgonigal com a publicação da obra "A realidade em jogo: Por que os games nos tornam melhores e como eles podem mudar o mundo".

As empresas, através de uma política de utilização do conceito de games transformaram procedimentos que já eram realizados em trabalhos divertidos, cativantes e estimulantes para os funcionários. Dessa maneira, o feedback foi facilitado para as empresas, por meio da percepção gerencial de indicadores de esforço e metas alcançadas.

São vários os mecanismos de jogos que compõe a Gamificação, podendo-se destacar: tarefas, feedback, objetivos, evolução pessoal, regras, informações, status, promoção, socialização, colaboração, risco, autonomia, narrativa e obstáculos.

Estes mecanismos, isoladamente ou em conjunto, são capazes de promover uma transformação no ambiente em que são aplicados por replicarem características de jogos em 
situações da vida comum, e trazerem para essas situações o mesmo ambiente envolvente, dinâmico, desafiador e imersivo dos jogos.

\title{
4 GAMEFICAÇÃO NA EDUCAÇÃo
}

Após anos de bons resultados no campo negocial, alguns educadores despertaram-se para o uso dos atributos da Gameficação no ensino. Várias destas mecânicas podem e devem ser aplicados no campo educacional como forma de resgate do interesse dos discentes. Sobre o tema ensina Marcelo Luis Fardo:

\begin{abstract}
Atualmente, a gamificação encontra na educação formal uma área bastante fértil para a sua aplicação, pois lá ela encontra os indivíduos que carregam consigo muitas aprendizagens advindas das interações com os games. Encontra também uma área que necessita de novas estratégias para dar conta de indivíduos que cada vez estão mais inseridos no contexto das mídias e das tecnologias digitais e se mostram desinteressados pelos métodos passivos de ensino e aprendizagem utilizados na maioria das escolas (FARDO, 2013, p.3).
\end{abstract}

Através de aulas mais atraentes e vibrantes é possível aumentar a consciência produtiva dos acadêmicos. A Gameficação se propõe a contribuir no alcance desses resultados através de suas características.

Através de uma maior interação na relação professor-aluno e aluno-aluno é superado o modelo atual de mera transmissão do conhecimento. Os alunos saem de uma posição passiva e são estimulados a buscar o conhecimento dentro e fora de sala de aula necessário para resolução de determinado desafio.

Quanto mais informações os alunos tiverem maior será a chance de solucionar determinado desafio proposto e obter a almejada recompensa, o que leva a um estímulo natural ao estudo do conteúdo.

O uso de elementos como missões, desafios, pontuações, rankings, prêmios compõe o chamado PBL (Points, badges and leaderboards), diretriz da aplicação dessa metodologia.

O ensino gameficado estimula a discussão entre os participantes durante a atividade e há a inclusão do componente lúdico, sendo mais que o brincar, pois envolve um criterioso planejamento docente, direcionado aos objetivos da aprendizagem (FARDO, 2013).

Alves, Minho e Diniz (2014), na obra Gamificação: diálogos com a educação realizaram uma extensa pesquisa, e concluíram uma interessante estratégia de utilização dessa metodologia, a ver: 
Conhecimento e experimentação de jogos:

- Conhecimento do público alvo

- Definição de um escopo

- Compreensão do problema e contexto

- Definição da missão e objetivo

- Desenvolvimento da narrativa

- Definição do ambiente-plataforma

- Definição de tarefas e mecânica

- Definição do sistema de pontuação

- Definição de recursos

-Revisão da estratégia

Abaixo estão especificadas as etapas e seus significados:

- Conhecimento e experimentação de jogos: os autores consideram importante que os professores conteudistas experimentem diversos jogos para compreenderem a mecânica que está por trás e as tecnologias disponíveis que permitem a interação com os jogos.

- Conhecimento do público alvo: análise do perfil dos alunos.

- Definição de um escopo: delimitar o tema, áreas envolvidas, competências e habilidades.

- Compreensão do problema e contexto: entendimento de como relacionar o problema de aprendizagem e conteúdos com problemas reais e explorá-los através do jogo.

- Definição da missão e objetivo: analisar se há clareza quanto à estratégia do jogo, missão, objetivos educacionais e tema. Verificar se há possibilidades de alcance e mensuração do atingimento dos objetivos.

- Desenvolvimento da narrativa: decisões relativas à estrutura da história, bem como sua aderência ao tema e contexto. Refletir sobre o quanto o aluno poderá se envolver com a história.

- Definição do ambiente-plataforma: Identificação da principal (e secundária) situação em que se dará a interação dos alunos com o jogo. Quais dispositivos poderão ser usados e onde. Por exemplo: notebook, tablet ou celular; em casa, no trabalho na sala de aula.

- Definição de tarefas e mecânica: Aqui é pensado o tempo de duração do jogo e a frequência de interações. É estabelecida a mecânica, tarefas e regras e como se adéquam à narrativa.

- Definição do sistema de pontuação: para os autores a pontuação deve ser equilibrada, justa e diversificada. É momento de definir recompensas e como será apresentado o ranking.

- Definição de recursos: de acordo com a estratégia estabelecida é necessário estudar a forma pela qual se dará a avaliação da aprendizagem: o professor precisará analisar cada tarefa ou haverá um sistema automático?

- Revisão da estratégia: É hora de revisar cada um dos pontos acima certificando-se que todos os aspectos atendem aos alunos e às necessidades de ensino-aprendizagem (ALVEZ, MINHO E DINIZ, 2014). 
A obra acima mostra como pode ser consistente um planejamento inovador no sentido da aplicação da gameficação, e aponta para uma real possibilidade de mudança no paradigma atual da educação.

\section{GAMEFICAÇÃO NO DIREITO}

O Direito é tradicionalmente uma Ciência que prima pelo apego às formas e à interpretação literal das leis. Neste sentido a introdução de metodologias inovadoras que representem uma desconstrução desse modelo dominante requer tempo e perseverança.

A gameficação deve ser utilizada de modo que suas características se associem a características semelhantes do mundo jurídico de modo a fornecer um ambiente de favorecimento à sua aplicação.

A seara jurídica é naturalmente um ambiente competitivo. O modelo tradicional jurídico aposta na litigiosidade, na disputa, no embate e não no consenso. Esta realidade pode reverberar positivamente para o ensino da matéria nas faculdades, sendo um ponto que merece atenção dos docentes, que poderão de forma organizada, otimizada e adequada estimular o aprendizado através de uma saudável competição.

A avaliação através de testes objetivos e dissertativos compõe quase todas as avaliações nesta ciência, seja no ramo acadêmico ou em concursos para obtenção de cargos públicos, gerando a noção competitiva nos estudantes desde sua entrada na faculdade.

Gameficar o ensino jurídico não deve ser confundido como a mera introdução de plataformas digitais ou tecnologias eletrônicas, porém estes artifícios não devem ser descartados ou malquistos, podendo servir como valiosas armas na efetivação dessa metodologia.

A divisão da sala em duplas ou grupos e a proposta de atividades em etapas bem divididas parece ser uma maneira interessante de gamificar o conteúdo a ser ministrado, pois permite aos alunos gradativamente absorverem o conhecimento, mantendo em nível elevado seu engajamento graças às tarefas com objetivos e recompensas em curto prazo.

A cada atividade realizada deve haver uma bonificação correspondente e é salutar que haja uma diversificação nos modelos de atividades propostas para fugir da linearidade típica do modelo formal de ensino.

O trabalho em equipe promoverá um estímulo na interação e compartilhamento de informações, consequentemente estes estudantes devem se sentir engajados a procurar 
autonomamente o conteúdo trabalhado. É uma significativa alteração no padrão de participação, de comportamento do aluno.

Esse modelo deve inverter a forma de alcançar o conhecimento. Os alunos não mais serão meros expectadores de um professor transmissor de um vasto conteúdo, mas serão protagonistas de seu próprio estudo.

Estas são apenas ideias sugestivas para uma melhor percepção da ideia que esta metodologia pretende implantar. Obviamente cada uma de suas características pode ser aplicada de inúmeras formas, que podem ser adequadas às características da turma ou de determinado estudante e dos recursos do professor.

Fato é que o conhecimento por si só já não é o único, tampouco melhor critério avaliativo, uma vez que o acesso a ele é cada vez mais democrático. A sociedade evoluiu, o Direito evoluiu, e a chave do sucesso está não mais em conhecer, mas sim em como esmerar esse conhecimento e como se dará a sua aplicação.

\section{EXEMPLOS DE GAMIFICAÇÃO DO DIREITO EM PLATAFORMAS DIGITAS}

Muito embora a gamificação no ensino jurídico ainda seja uma promessa a se cumprir, já existem algumas empresas que, acreditando nessa metodologia inovadora, disponibilizaram no mercado produtos já prontos para facilitar a aderência dos estudantes e impulsionar a formação acadêmica e/ou profissional.

Neste sentido temos o Juris Game ${ }^{6}$, uma plataforma digital em que os estudantes participam em conjunto de um caso fictício. Ao representarem acusação e defesa eles: exploram e aprendem o conteúdo jurídico da causa, compartilham informações relativas à disciplina, interagem, e se sentem desafiados a vencê-la.

Outro exemplo de imersão tecnológica no Direito é o site Instituto Diálogo ${ }^{7}$ que tem uma atuação bem definida de acordo com Marcio Caldas no artigo intitulado "Gamification e o Direito":

O Instituto Diálogo tem sido pioneiro na utilização de games para o treinamento de estudantes e profissionais do direito. Em parceria com a Games Acadêmicos, o ID tem organizado cursos in company nos escritórios e departamentos jurídicos que usam a metodologia dos games, além de também oferecer consultorias para a realização de moot courts em diversas faculdades e bancas de advocacia. Algumas instituições de ensino também contrataram o ID para a

\footnotetext{
${ }^{6}$ Disponível em: < http://www.jurisgame.com.br/jurisgame/prepara.htm>. Acesso em: 07 abr. 2018.

${ }^{7}$ Disponível em: < http://institutodialogo.com.br/ >. Acesso em: 07 abr. 2018.
} 
inclusão de games na sua grade curricular como componentes da avaliação da disciplina (CALDAS, 2015).

O autor explica também como a plataforma funciona:

No Instituto Diálogo e na Games Acadêmicos ${ }^{8}$ desenvolvemos algumas práticas que vêm despertando efeitos bastante positivos. Desenvolvemos uma plataforma digital que simula o processo judicial eletrônico - . A prática tem nos mostrado que a ferramenta possibilita elevarmos o simples ensino técnico e formal de peticionamento a um exercício prático de argumentação jurídica. Isto é possível porque o nível de engajamento é elevado para produzir argumentos que sejam melhores dos que de seus pares. Um modelo de petição pode substituir, muitas vezes, uma aula, mas os argumentos que serão inseridos nesse modelo é que serão determinantes (CALDAS, 2015).

Para aprimorar os estudos acadêmicos ou para concursos públicos também foi desenvolvido o AppProva ${ }^{9}$, aplicativo que pode ser acessado online a qualquer hora e qualquer lugar através de computadores, tablet's, smartphones e afins. Através do aplicativo os estudantes podem estudar individualmente ou podem travar desafios em duplas, em que respondem perguntas sobre determinada disciplina e vão obtendo pontuações que variam de acordo com o tempo de resposta. Após a resposta surgir, há uma explicação teórica e ao final de todas as perguntas é eleito o vencedor da disputa.

$\mathrm{O}$ aplicativo Endireitados ${ }^{10}$ também é voltado para o exame da Ordem dos Advogados do Brasil (OAB) e garante ao aluno um ambiente imersivo de aprendizado fora da sala de aula através dos mecanismos que a tecnologia promove para lazer, agregando valor educativo aos mesmos.

Assim, como se pode ver, já existem algumas experiências bem estruturadas de gamefication na seara jurídica. Dentro de sala de aula, contudo, sem a utilização de subsídios eletrônicos ainda é bastante incipiente. Embora seja plenamente possível sua aplicação sem os meios eletrônicos, mas ainda assim valendo-se das mecânicas de jogos, a gamificação ainda é aplicada apenas isoladamente em uma ou outra instituição, por um ou outro professor de pensamento mais vanguardista.

\footnotetext{
${ }^{8}$ Disponível em: < https://www.facebook.com/gamesacademicos/ >. Acesso em: 07 abr. 2018.

${ }^{9}$ Disponível em: < http://appprova.com.br/ >. Acesso em: 07 abr. 2018.

${ }^{10}$ Disponível em:< http://www.endireitados.com.br/ >. Acesso em: 07 abr. 2018.
} 


\section{CONCLUSÃO}

A evolução do sistema de ensino vigente passa necessariamente por uma reformulação geral nas metodologias acadêmicas. Um modelo como o atual, centenário, obsoleto e cartesiano significa que não acompanhou a evolução da sociedade, dos estudantes e das formas de acesso ao conhecimento. A forma transmissiva de conhecimento não é mais tão efetiva quanto outrora, e uma dentre as várias razões são os mecanismos eletrônicos que “competem" pela atenção dos alunos, gerando um desestímulo nestes e consequentemente dos professores, o que gera um ciclo pernicioso prejudicial a toda cadeia educativa.

A falência gradativa do sistema de ensino jurídico gera reflexos severos na qualificação dos profissionais do Direito. Os óbices abarcam tanto a aprovação nos diversos exames que esta profissão permite, como o exame da $\mathrm{OAB}$ e concursos públicos, quanto à atuação profissional futura destes juristas.

Destarte, é urgente a necessidade de atualização dos alicerces do ensino nas faculdades de Direito, e esta modernização passa, entre outros fatores, pela introdução de metodologias inovadoras.

É amplo o rol de metodologias possíveis de serem aplicadas ao ensino jurídico e para o presente estudo foi escolhida a Gameficação.

As características dos jogos, de acordo com o presente estudo, levam a uma alta aderência dos mesmos em todas as faixas etárias. Logo, a identificação com o ambiente de games no ensino aponta para uma predisposição de adesão mais fácil entre discentes e docentes ao criar um ambiente imersivo propenso ao desenvolvimento cognitivo.

Ao explorar características como a ludicidade, competição, interatividade e recompensas, a gamefication sugere uma migração do modelo instrucionista (transmissão de conhecimento professor-aluno) para o modelo construcionista do conhecimento, em que o aluno passa a ser o protagonista do conhecimento, tendo mais autonomia e se sentindo mais engajado e com papel ativo na construção do mesmo. Neste modelo há uma maior interação entre os próprios alunos e também na relação professor-aluno.

Ainda que a presente obra tenha enfatizado a não restrição ao uso de mecanismos eletrônicos, a realidade ainda insípida desta metodologia no ensino jurídico aponta para seu desenvolvimento de forma mais substancial sob esta perspectiva.

Não se deve, contudo, esquecer que a utilização dessa metodologia em sala de aula está diretamente ligada à criatividade do professor e dispensa artefatos eletrônicos para sua 
efetivação. Basta a inserção da mecânica dos games em sala de aula como ludicidade, competição, recompensas, interação, autonomia entre outras e será possível vislumbrar um maior engajamento por parte dos alunos.

Efetivar e estimular a gameficação no ensino jurídico não se trata de veleidades, seus passos iniciais sugerem um futuro bem interessante e promissor. É necessário que as faculdades compreendam e promovam a necessidade de implementação dessa e de outras metodologias inovadoras, pois possibilitará a concretização da teoria e apontará para futuras problemáticas que poderão ser trabalhadas para o aperfeiçoamento na aplicação das mesmas.

\section{REFERÊNCIAS}

ALVES, L.R.G.; MINHO, M.R. DA S.; DINIZ, M.V.C. Gamificação: diálogos com a educação. In L. M. Fadel et al., EDS. 2014, Gamificação na educação. Florianópolis: Pimenta Cultural, 2014.

BARATA, G. et al. Melhorando o ensino universitário com a gamificação. In: PORTUGUESE CONFERENCE ON HUMAN-MACHINE INTERACTION, 5, 2013, Vila Real. Interacção. 2013.

BASSANI, P.S.; PASSERINO, L.M.; PASQUALOTI, P.R.; RITZEL, M.I (2006) Em Busca de uma Proposta Metodológica para o Desenvolvimento de Software Educativo Colaborativo. Novas Tecnologias na Educação, CINTED-UFRGS, V.4, N.1, Julho 2006, pp.1-10.

BECKER, Fernando. $O$ que é construtivismo? In: BORJA, Amélia de et al. Construtivismo em revista. São Paulo: FDE, 1993. p. 87-93 (Série Idéias, 20).

BENEDITO, Luiza Machado Farhat; GABRICH, Frederico de Andrade. Lego Serious Play no Direito. Revista de Direito de Família e Sucessão, v.3, n.1, 2017, p.33-53. Disponível em: < http://www.indexlaw.org/index.php/direitofamilia/article/view/1944 >. Acesso em: 07 abr. 2018.

BENEDITO, Luiza Machado Farhat; GABRICH, Frederico de Andrade. Lego Serious Play na solução de problemas familiares e societários. Revista de Pesquisa e Educação Jurídica, v.2, n.2, 2016, p.105-126. Disponível em: http://indexlaw.org/index.php/rpej/article/view/1310/pdf >. Acesso em: 03 abr. 2017.

CALDAS, Marcio. Gamification e o Direito. 2015. Disponível em: https://jota.info/artigos/gamification-e-o-direito-09092015. Acesso em: 19 jun. 2017.

FARDO, M. L. A gamificação aplicada em ambientes de aprendizagem, 9 CINTED-

FREIRE, Paulo. Pedagogia da autonomia: saberes necessários à prática educativa. 51. ed. São Paulo: Paz e Terra, 2015. 
GABRICH, Frederico de Andrade. Transdisciplinaridade no ensino jurídico. Publica Direito. 2013. Disponível em: http://www.publicadireito.com.br/artigos/?cod=57db7d68d5335b52. Acesso em: 12 jun. 2017.

GABRICH, Frederico de Andrade. Inovação no Direito / Frederico de Andrade Gabrich (coord.). Belo Horizonte: Universidade Fumec. Faculdade de Ciências Humanas, Sociais e da Saúde, 2012.464 p.

GALEGALE, Gustavo Perri. A utilização de gamification em um sistema de informação: estudo de caso da Natura Cosméticos S.A/ Gustavo Perri Galegale - São Paulo, 2014. 110 p.

KAPP, L. The Gamification of Learning and Instruction: Game-based Methods and Strategies for Training and Education [S.1]: Wiley, 2012. ISBN 9781118191989.

KRISTIANSEN, PER; RASMUSSEN, Robert. Construindo um negócio melhor com a utilização do Método LEGO Serious Play. São Paulo: DVS editora, 2015.

LEGO Group. The science of lego serious play. 2002. Disponível em: www.seriousplay.com Acesso em: 17 mar. 2017.

MORIN, Edgar. Os sete saberes necessários à educação do futuro [livro eletrônico]. São Paulo: Cortez; Brasília: Unesco, 2013.

MUSSIO, Simone Cristina; VALIDÓRIO, Valéria Cristiane; MERLINI, Véra Maria Ferro. As novas tecnologias acopladas à educação: Reflexões sobre o ensino-aprendizagem no século XXI. Revista RETC, n. 14, p. 44-52, abr. 2014. Disponível em: <http://revistafatecjd.com.br/retc/index.php/RETC/article/view/127/pdf>. Acesso em: 3 abr. 2017.

RIBEIRO, Luis Roberto de Camargo. Aprendizagem baseada em problemas (PBL): uma experiência no ensino superior [livro eletrônico]. São Carlos: EdUFSCar, 2008.

SASS, Odair. Construtivismo e Currículo. Artigo digital. Disponível em: http://www.crmariocovas.sp.gov.br/pdf/ideias_26_p087-103_c.pdf. Acesso em: 11 mar. 2016. UFRGS Novas Tecnologias na Educação. V.11 N 1, p. 1-9. 2013julho, 2013. Disponível em: http://seer.ufrgs.br/renote/article/viewFile/41629/26409 - página 3. Acesso em 19 jun. 2017.

VIANNA, Ysmar. Gamification, Inc: como reinventar empresas a partir de jogos /Ysmar Vianna ... [et al.]. - 1. Ed. - Rio de Janeiro: MJV Press, 2013. 116p.; e-book.

VALENTE, J.A (1993). Computadores e Conhecimento: repensando a educação. Gráfica UNICAMP. Campinas.p.418, 1993.

ZEVE, C.M.D et al (2000) Aprendizagem Colaborativa: A utilização de CD-ROM e Internet em um Sistema Integrado. XI Simpósio Brasileiro de Informática na Educação. Maceió. 2000. 